TITLE:

\title{
Micro-patterning of Si(100) surfaces by ethanol cluster ion beams
}

$\operatorname{AUTHOR}(\mathrm{S})$ :

Takaoka, Gikan H.; Ryuto, Hiromichi; Ozaki, Ryosuke; Mukai, Hiroshi; Takeuchi, Mitsuaki

\section{CITATION:}

Takaoka, Gikan H. ... [et al]. Micro-patterning of Si(100) surfaces by ethanol cluster ion beams. Surface and Coatings Technology 2011, 206(5): 869-873

ISSUE DATE:

2011-11

URL:

http://hdl.handle.net/2433/151703

\section{RIGHT:}

(C) 2011 Elsevier B.V.; This is not the published version. Please cite only the published version.; この論文は出版社版でありません。引用の際に は出版社版をご確認ご利用ください。 


\title{
Micro-Patterning of Si(100) Surfaces by Ethanol Cluster Ion Beams
}

\author{
Gikan H. Takaoka, Hiromichi Ryuto, Ryosuke Ozaki, Hiroshi Mukai
} and Mitsuaki Takeuchi

Photonics and Electronics Science and Engineering Center, Kyoto University

Katsura, Nishikyo-ku, Kyoto 615-8510, Japan

Tel:+81-75-383-2329, Fax:+81-75-383-2343, Email:gtakaoka@kuee.kyoto-u.ac.jp

\begin{abstract}
The irradiation of Si(100) surfaces by ethanol cluster ion beams exhibited high-rate sputtering and low-damage formation. The sputtered depth increased with increase of the acceleration voltage for ethanol cluster ions, and the sputtering yield was a few hundreds times larger than that by Ar monomer ion beams. Also, the RBS channeling measurement showed that the irradiation damage was much less than that by Ar monomer ion irradiation. Furthermore, the AFM image showed that the surface roughness of the irradiated Si(100) surface was less than $1 \mathrm{~nm}$. As well as the $\mathrm{Si}(100)$ surface, the sputtered depth of the photoresist surface increased with increase of the acceleration voltage for ethanol cluster ions.

Based on these results, micro-patterning with various sizes in a range of $3 \mu \mathrm{m}$ to $100 \mu \mathrm{m}$ was performed on the $\mathrm{Si}(100)$ surfaces by the ethanol cluster ion irradiation. Various kinds of photo-resist mask patterns such as circle, square and line patterns were made on a $\mathrm{Si}(100)$ surface by photo-resist technique. The SEM observation showed that micro-patterns were prepared on the $\mathrm{Si}(100)$ surface by the ethanol cluster ion irradiation.
\end{abstract}

Keywords: Ethanol cluster, Ion beam, Sputtering, Surface modification, Silicon, Photo-resist film 


\section{Introduction}

Ion beam process utilizing nano-size particle beams has attracted much interest as a nano-process technology [1-6]. It has several advantages, one of which is that the ion beams can transfer the energy as well as the charge. Furthermore, it is possible to control the incident energy and the ion current by adjusting the acceleration voltage, and the ion beams can be applied to the surface treatment of materials such as surface etching and surface smoothing. Another advantage is that the ion beams can transfer the mass and the material property, which is not available in electron beams or laser beams. As a result, various kinds of ions can be used for surface modification of materials by ion beam deposition or ion implantation. On the other hand, it is very hard to transfer high current of ion beams with low energy, because the space charge effect is enhanced. Also, high-rate sputtering by the ion beams is useful for surface treatment. However, it causes much irradiation damage on the surface. The high-rate sputtering and the low-damage formation represent a trade-off relationship, and the development of a novel beam process achieving both requests has received more attention.

In order to give breakthrough for above limitations embedded in the conventional ion beam process, cluster ion beam process has been developed [7]. In this process, equivalently low-energy and high-current ion beams can be realized using cluster ion beams. Also, during impact of cluster ions on a solid surface, the high-energy-density deposition and the collective motions of cluster atoms are achieved. As a result, the cluster ion beam process can be applied to the surface treatment with high-rate sputtering and low-damage formation. In addition, liquid cluster ion beams have exhibited significantly high-sputtering yields for various kinds of solid surfaces [8,9], and this feature is ascribed to chemical effects in sputtering of material surfaces. In particular, the chemical effects are enhanced using various kinds of radicals such as hydroxyl, alkyl and carbonyl groups, which are available as a component radical in liquid material. In this article, the sputtering of $\mathrm{Si}(100)$ substrates as well as photo-resist films is investigated using ethanol cluster ion beams. Also, irradiation damage and surface roughness are described. In comparison with Ar monomer ion beams, 
irradiation effects of the ethanol cluster ion beams are discussed. Furthermore, the formation of micro-patterning on a $\mathrm{Si}(100)$ surface is demonstrated with the ethanol cluster ion beams.

\section{Experimental Procedure}

Figure 1 shows the schematic illustration of the liquid luster ion beam system. It consists of four chambers such as source chamber, differential chamber, ionization chamber and target chamber. Liquid material such as ethanol is introduced into the cluster source, and it is heated up to $150^{\circ} \mathrm{C}$ by a wire heater attached around the source. The vapors of ethanol are ejected through a nozzle into a vacuum region. When the vapor pressure is high, an adiabatic expansion phenomenon occurs. The size of ethanol clusters produced by adiabatic expansion was distributed between a few hundreds and a few tens of thousands, and the average size (peak size) was approximately 1000 molecules. They pass through a collimator and enter an ionizer. In the ionizer, neutral ethanol clusters are ionized by an electron bombardment method. The electron voltage for ionization $(\mathrm{Ve})$ was adjusted between $0 \mathrm{~V}$ and $300 \mathrm{~V}$, and the electron current for ionization (Ie) was adjusted between $0 \mathrm{~mA}$ and 250 $\mathrm{mA}$. The ethanol cluster ions are accelerated toward a substrate, which is set on a substrate holder. The acceleration voltage $(\mathrm{Va})$ was adjusted between $0 \mathrm{kV}$ and $10 \mathrm{kV}$. The ion dose to the substrates is determined based on the ion current measured. When the desired ion dose is attained, the shutter is closed to terminate ion irradiation. The substrates used were $\operatorname{Si}(100)$ wafers and photo-resist films. The photo-resist films were prepared on $\mathrm{Si}(100)$ substrates by a spin coating method, and the film thickness was approximately $1 \mu \mathrm{m}$. The surface morphology of the $\operatorname{Si}(100)$ substrates and the photo-resist films sputtered by the ethanol cluster ions was observed by the atomic force microscope (AFM). Furthermore, the irradiation damage of the $\mathrm{Si}(100)$ substrates was measured by the Rutherford backscattering spectrometry (RBS) channeling method.

With regard to the photo-resist mask, it was commercially available by Yamanaka Semiconductor Co. Ltd. Various kinds of mask patterns such as circle, square and line 
patterns were made on a $\mathrm{Si}(100)$ substrate by photo-resist technique. The size of patterns was in a range of $3 \mu \mathrm{m}$ to $100 \mu \mathrm{m}$. The thickness of the photo-resist film coated was $1.2 \mu \mathrm{m}$. Ethanol cluster ions were irradiated on the mask-patterned surface of the Si (100) substrate. The irradiated surface with and without the photo-resist mask was investigated by the scanning electron microscope (SEM) observation.

\section{Results and Discussion}

It is well known that the wet process using organic liquid materials has been applied to the surface treatment for $\mathrm{Si}$ substrates. However, etching by organic liquid materials, such as ethanol, is not achieved even at elevated temperatures. Compared with a wet process, a dry process has several advantages such as integration and combination of various processes employed in a vacuum. Furthermore, in the cluster ion beam process using liquid material, another feature such as high-rate sputtering and low-damage formation, which is not obtained in conventional monomer ion beam process, is expected. In order to investigate etching and sputtering process of $\mathrm{Si}$ substrates, the ethanol cluster ions were irradiated on the substrate surface by changing the acceleration voltage.

Figure 2 shows the dependence of sputtered depth for $\mathrm{Si}(100)$ substrates and photo-resist films on the acceleration voltage. The ion dose was $1.0 \times 10^{16} \mathrm{ions} / \mathrm{cm}^{2}$, and the cluster size adjusted by the retarding voltage $(\mathrm{Vr})$ was larger than 100 molecules per cluster. As shown in the figure, the sputtered depth increases with increase of the acceleration voltage. When the acceleration voltage is $9 \mathrm{kV}$, the sputtered depth is $475 \mathrm{~nm}$ for $\mathrm{Si}$ and $498 \mathrm{~nm}$ for photoresist, respectively. Taking account of the sputtered depth and the ion dose, the sputtering yield can be calculated by estimating the density of Si such as $2.42 \mathrm{~g} / \mathrm{cm}^{3}$. The sputtering yield of $\mathrm{Si}$ at an acceleration voltage of $9 \mathrm{kV}$ is 246 atoms per ion, which is a few hundreds times larger than that by argon (Ar) ion beam sputtering. This is ascribed to the chemical sputtering of the Si surfaces by the ethanol cluster ion beams, in which hydrogen atoms and alkyl radicals have important roles. They react with the Si surface atoms as follows;

$$
\mathrm{C}_{2} \mathrm{H}_{5} \mathrm{OH} \rightarrow \mathrm{C}_{2} \mathrm{H}_{5} \mathrm{O}+\mathrm{H}
$$




$$
\begin{aligned}
& \mathrm{C}_{2} \mathrm{H}_{5} \mathrm{O} \rightarrow \mathrm{C}_{2} \mathrm{H}_{5}+\mathrm{O} \\
& \mathrm{C}_{2} \mathrm{H}_{5} \rightarrow \mathrm{CH}_{2}+\mathrm{CH}_{3} \\
& \mathrm{Si}+\mathrm{mH} \rightarrow \mathrm{SiH}_{\mathrm{m} \uparrow} \\
& \mathrm{Si}+\mathrm{nCH}_{3} \rightarrow \mathrm{Si}\left(\mathrm{CH}_{3}\right)_{\mathrm{n}} \uparrow
\end{aligned}
$$

In the chemical reaction, the silicon hydride and silicon hydro-carbide materials as volatile compounds are ejected from the substrate surface.

Figure 3 shows the surface morphology of (a) $\mathrm{Si}(100)$ substrates and (b) photo-resist films sputtered by ethanol cluster ion beams. The acceleration voltage was $6 \mathrm{kV}$, and the ion dose was $1.0 \times 10^{16}$ ions $/ \mathrm{cm}^{2}$. AFM images for unirradiated surfaces are also shown, and the surface roughness $(\mathrm{Ra})$ is $0.18 \mathrm{~nm}$ for the $\mathrm{Si}$ surface and $0.17 \mathrm{~nm}$ for the photo-resist surface, respectively. As shown in the figure, the sputtered $\mathrm{Si}$ surfaces become rough, and the surface roughness is $0.93 \mathrm{~nm}$. For the chemical sputtering by the ethanol cluster ion irradiation, the surface roughness increased with increase of the sputtered depth. However, it should be noted that the smooth surface with a roughness less than $1 \mathrm{~nm}$ is obtained. On the other hand, for the photo-resist films irradiated at an acceleration voltage of $6 \mathrm{kV}$, the surface roughness is $0.48 \mathrm{~nm}$. Furthermore, the surface roughness increased with increase of the acceleration voltage, and it was $0.96 \mathrm{~nm}$ at an acceleration voltage of $9 \mathrm{kV}$.

Figure 4 shows the number of displacement atoms for the $\mathrm{Si}(100)$ surfaces irradiated at different acceleration voltages by ethanol cluster ion and by Ar monomer ion. The ion dose was $1.0 \times 10^{15}$ ions $/ \mathrm{cm}^{2}$. The number of displacement atoms for the ethanol cluster ion irradiation is less than that for the Ar monomer ion irradiation at the same acceleration voltage. With regard to the ethanol cluster ion irradiation, the incident energy of an ethanol molecule is the accelerating energy divided by the cluster size, and it is very low. Therefore, the irradiation damage induced by ethanol cluster ion beams is less than that by $\mathrm{Ar}$ monomer ion beams. In addition, at an acceleration voltage of $1 \mathrm{kV}$, the number of displacement atoms by the ethanol cluster ion irradiation is the same as that of the unirradiated Si surface. Because the incident energy of an ethanol molecule is less than 10 
$\mathrm{eV}$, the damage-free surface is obtained by extremely low energy irradiation of the ethanol cluster ion beams.

As an engineering application of high-rate sputtering by the ethanol cluster ion beams, patterning process was performed on the $\mathrm{Si}(100)$ surface with a photo-resist mask. Figure 5 shows the line patterns demonstrated with the ethanol cluster ion beams. The acceleration voltage was $9 \mathrm{kV}$, and the ion dose was approximately $5.0 \times 10^{15} \mathrm{ions} / \mathrm{cm}^{2}$. After the ethanol cluster ion irradiation, the photo-resist film on the $\mathrm{Si}(100)$ surface was removed by acetone rinsing. As shown in the figure, the edge with a line width of $3 \mu \mathrm{m}$ is straight, and the micro-pattern is clearly made by the ethanol cluster ion irradiation. Although the sputtered depth is approximately $200 \mathrm{~nm}$, the side wall is not straight. This might be due to redeposition of the Si atoms sputtered from the bottom plane onto the side wall, which seems to occur within the small distance less than approximately $100 \mathrm{~nm}$ from the edge.

Figure 6 shows SEM images for plane views of circle and square patterns with (a) convex pattern and (b) concave pattern. The acceleration voltage was $9 \mathrm{kV}$, and the ion dose was approximately $5.0 \times 10^{15}$ ions $/ \mathrm{cm}^{2}$. The diameter of circle and the edge length of square was $60 \mu \mathrm{m}$, respectively, and the spacing for both the circle and square patterns was $10 \mu \mathrm{m}$. As shown in the figure, the edge is sharp, and the sputtered surface (bright area) represents the flat plane. With regard to the convex and concave patterns, both patterns are similar to the mask patterns. This is ascribed to the chemical sputtering of Si surface, which is occurred preferentially rather than the physical sputtering. The volatile particles ejected from the $\mathrm{Si}$ surface might be evaporated in normal direction, even after they migrate and move toward the corner or the edge of the pattern.

\section{Conclusion}

The ethanol cluster ion beams were irradiated at different acceleration voltages on Si(100) surfaces, and the sputtered depth and the surface morphology were investigated. The sputtered depth increased with increase of the acceleration voltage, and the sputtering yield was a few hundreds times larger than that by Ar monomer ion irradiation. The high- 
rate sputtering was due to the chemical erosion and sputtering by the ethanol cluster ion irradiation. Although the surface roughness became larger compared with the unirradiated surface, it was less than $1 \mathrm{~nm}$. Furthermore, the RBS channeling measurement showed that the irradiation damage was less than that by Ar monomer ion irradiation. This was due to the low-energy irradiation effect by the ethanol cluster ion beams.

Based on these results, micro-patterning with various sizes in a range of $3 \mu \mathrm{m}$ to $100 \mu \mathrm{m}$ was demonstrated on the $\mathrm{Si}(100)$ surfaces by the ethanol cluster ion irradiation. Various kinds of mask patterns such as circle, square and line patterns were made on the $\operatorname{Si}(100)$ surface by photo-resist technique. The SEM observation showed that micro-patterns corresponding to the photo-mask patterns were prepared by the ethanol cluster ion irradiation.

\section{Acknowledgements}

The authors are grateful to the Quantum Science and Engineering Center of Kyoto University for the RBS measurement. Furthermore, a part of the work such as SEM observation was supported by "Nanotechnology Support Project" of the Ministry of Education, Culture, Sports, Science and Technology (MEXT), Japan. 
References

1) B. Colombeau, S.H. Yeong, D.X.M. Tan, A.J. Smith, R.M. Gwilliam, C.M. Ng, K.R.C. Mok, F. Benistant and L. Chan, Proc. 17th Int. Conf. on Ion Implant. Technol. (IIT2008), (AIP Conf. Proc.), Vol. 1066 (2008) p.11.

2) J. Ishikawa, Rev. Sci. Instr., 79 (2008) Art. No. 02C506.

3) F.W. Meyer, H. Zhang, L.I. Vergara and H.F. Krause, Nucl. Instr. Methods, B258 (2007) 264.

4) T. Yotoriyama, A. Nakao, Y. Suzuki, T. Tsukamoto and M. Iwaki, Nucl. Instr. Methods, B242 (2006) 51.

5) J.O. Borland, Nucl. Instr. Methods, B237 (2005) 6.

6) J.E. Greene, Mater. Res. Bull. 26 (2001) 777.

7) I. Yamada and G.H. Takaoka, Jpn. J. Appl. Phys., 32 (1993) 2121.

8) G.H. Takaoka, M. Kawashita, H. Noguchi and K. Nakayama, Surf. Coat. Technol., 201 (2007) 8628,

9) H. Ryuto, K. Sugiyama, R. Ozaki and G.H. Takaoka, Appl. Phys. Exp., 2(1) (2009) Art. No. 016504 
Figure Captions

Figure 1: Schematic illustration of the liquid luster ion beam system.

Figure 2: Dependence of sputtered depth for $\operatorname{Si}(100)$ substrates and photo-resist films on the acceleration voltage. The ion dose was $1.0 \times 10^{16} \mathrm{ions} / \mathrm{cm}^{2}$.

Figure 3: Surface morphology of (a) Si(100) substrates and (b) photo-resist films sputtered by ethanol cluster ion beams. The acceleration voltage was $6 \mathrm{kV}$, and the ion dose was $1.0 \times 10^{16} \mathrm{ions} / \mathrm{cm}^{2}$.

Figure 4: Number of displacement atoms for the $\mathrm{Si}(100)$ surfaces irradiated at different acceleration voltages by ethanol cluster ion and by Ar monomer ion. The ion dose was $1.0 \times 10^{15} \mathrm{ions} / \mathrm{cm}^{2}$.

Figure 5: SEM images for (a) the plane view and (b) the cross-section view of line patterns demonstrated with ethanol cluster ion beams. The acceleration voltage was $9 \mathrm{kV}$.

Figure 6: SEM images for the plane views of circle and square patterns with (a) convex and (b) concave patterns. The acceleration voltage was $9 \mathrm{kV}$. 


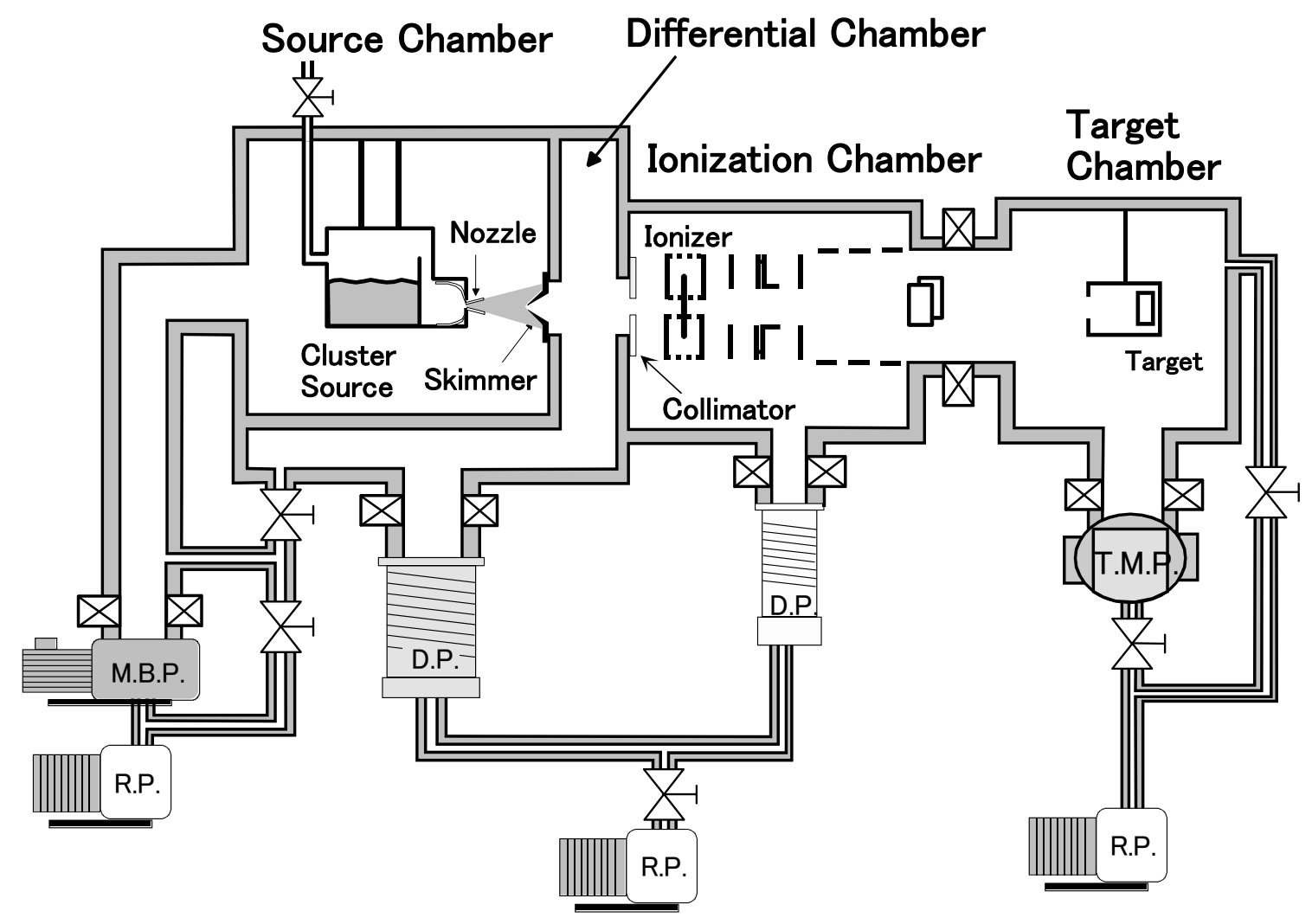

Figure 1: Takaoka et al. 


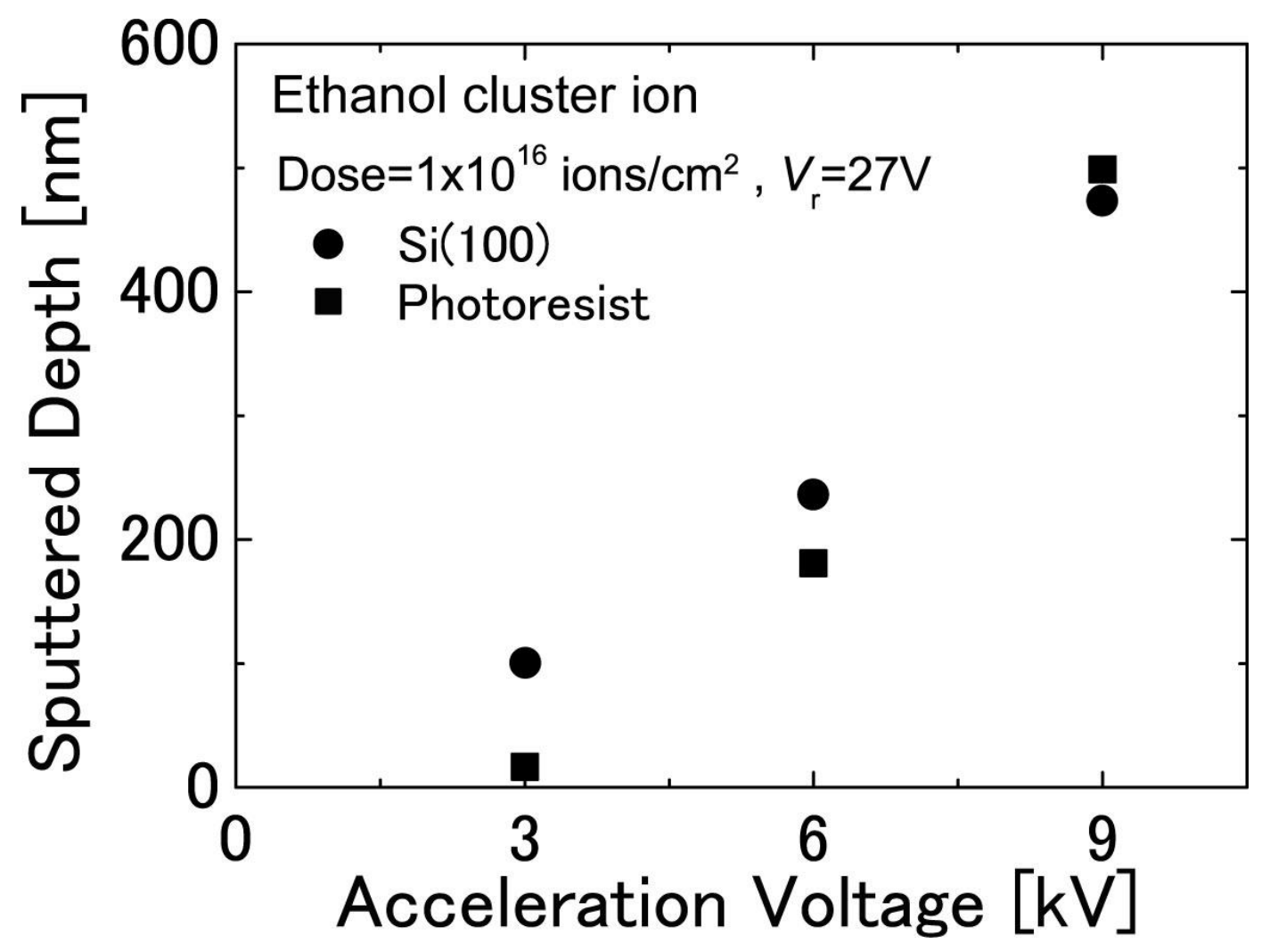

Figure 2: Takaoka et al. 
(a) $\mathrm{Si}(100)$

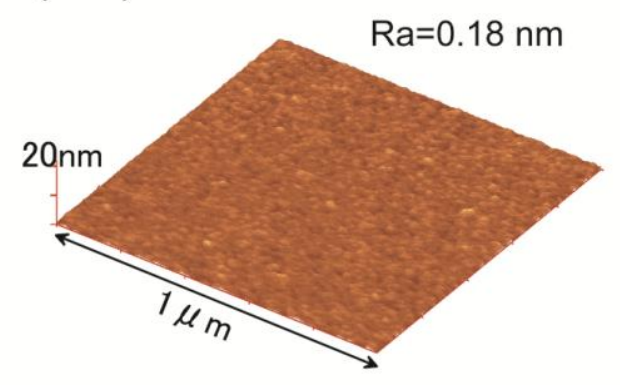

Unirradiated

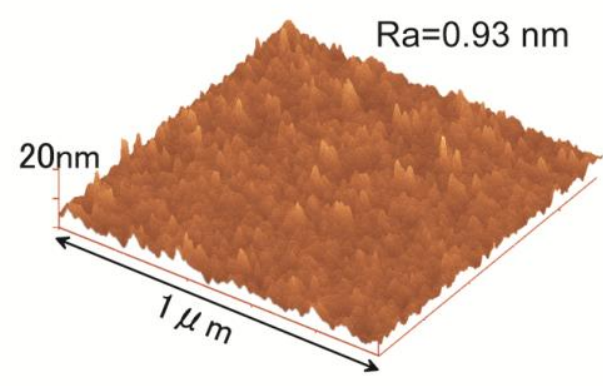

Ethanol cluster

$V_{\mathrm{a}}=6 \mathrm{kV}$, dose $=1 \times 10^{16}$ ions $/ \mathrm{cm}^{2}$ (b) Photoresist

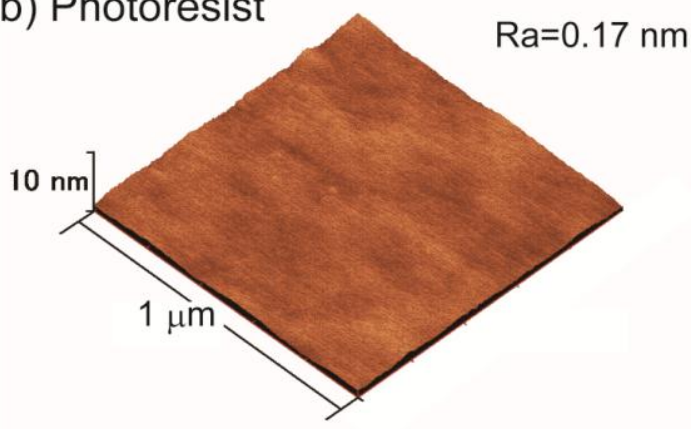

Unirradiated

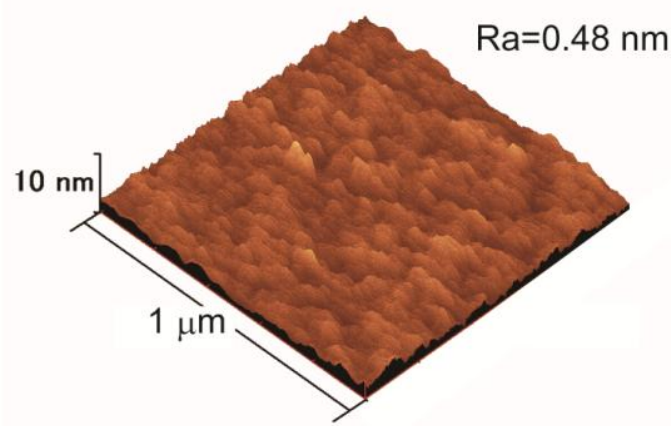

Ethanol cluster

$V_{\mathrm{a}}=6 \mathrm{kV}$, dose $=1 \times 10^{16}$ ions $/ \mathrm{cm}^{2}$

Figure 3: Takaoka et al. 


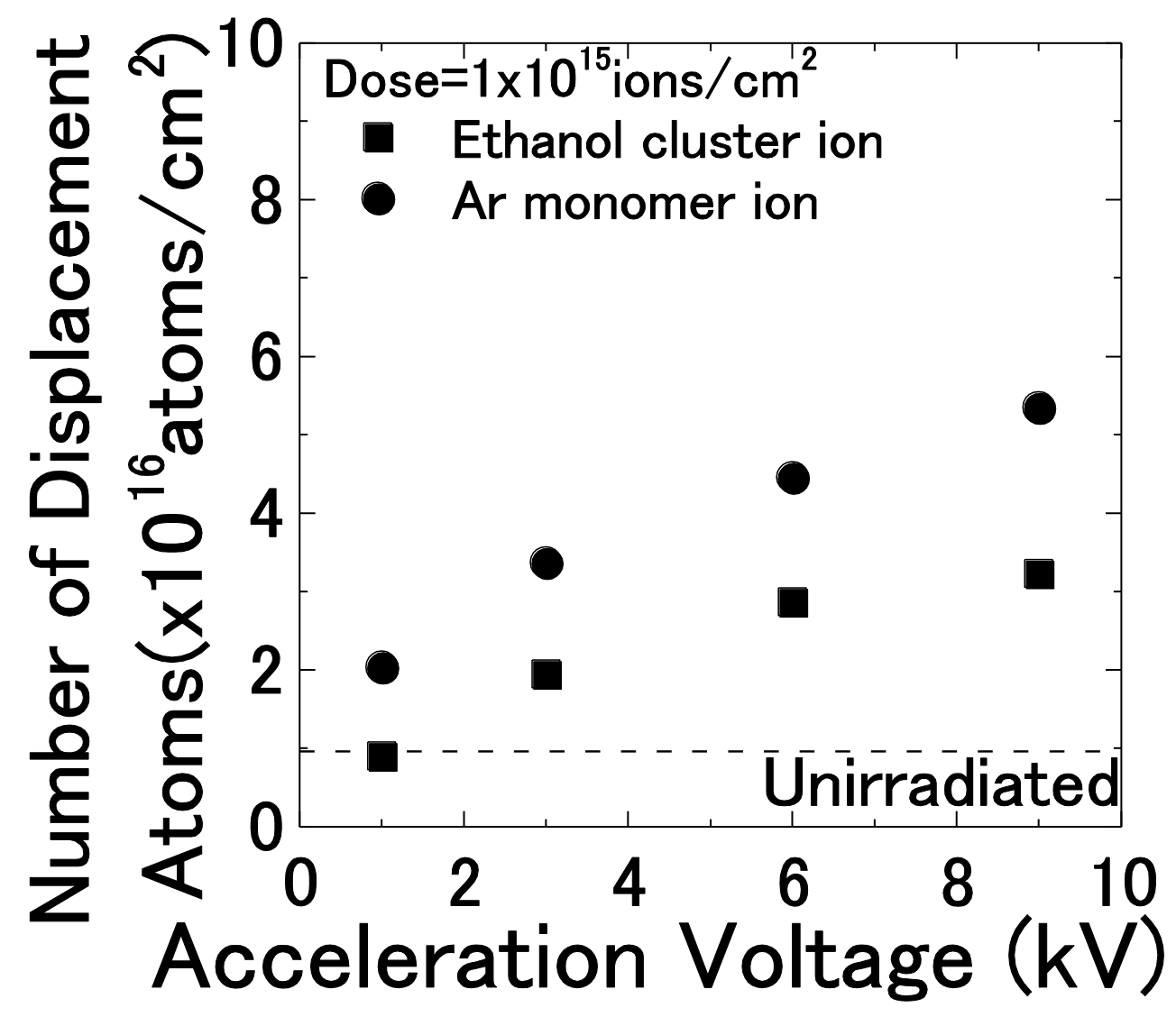

Figure 4: Takaoka et al. 
(a) Plane view
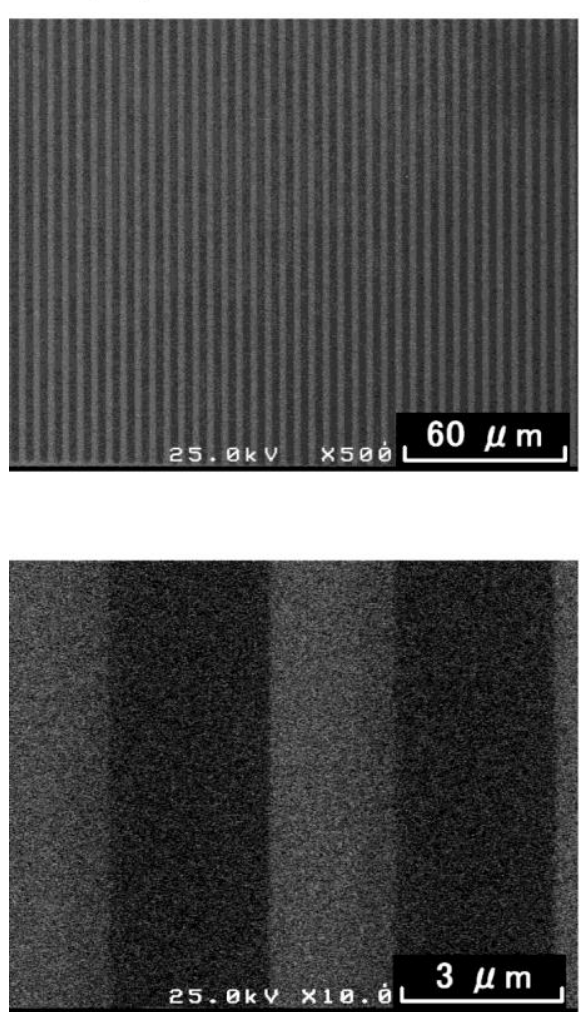

(b) Crosssection view
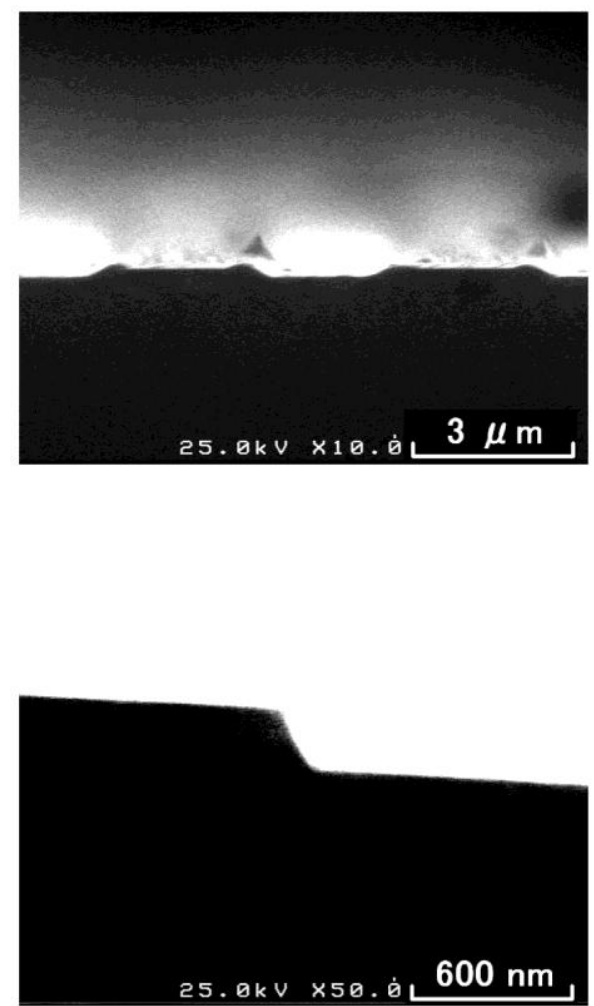

\section{(Line pattern)}

Figure 5: Takaoka et al. 
(a) (Convex pattern)

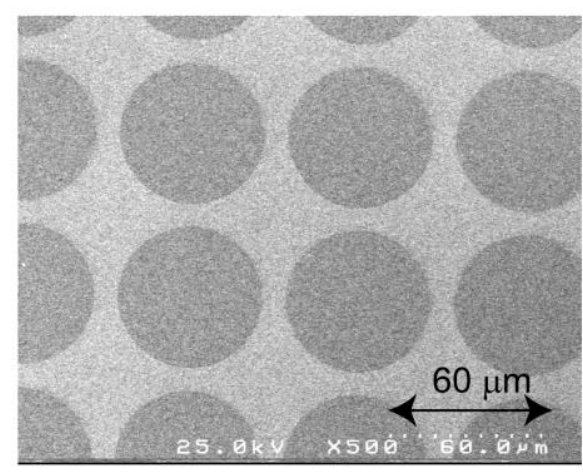

(b) (Concave pattern)

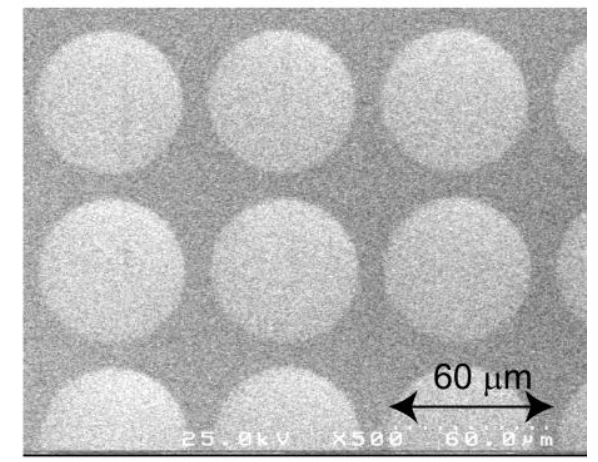

(Circle pattern)
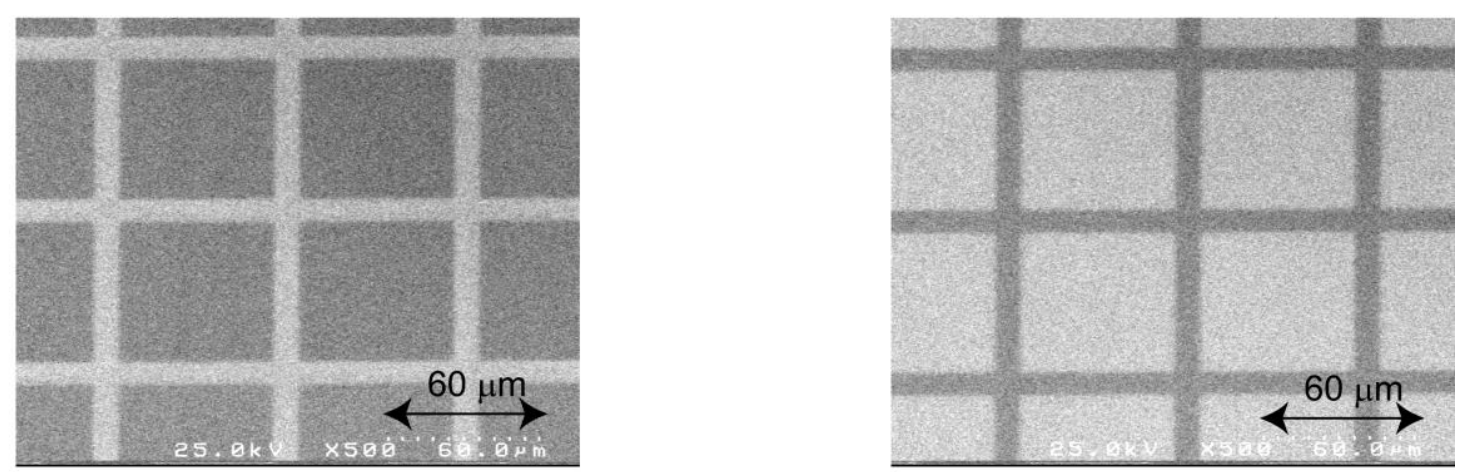

(Square pattern)

Figure 6: Takaoka et al. 